JIKSH: Jurnal Ilmiah Kesehatan Sandi Husada
https://akper-sandikarsa.e-journal.id/JIKSH
Volume 10| Nomor 1| Juni|2021
e-ISSN: 2654-4563 dan p-ISSN: 2354-6093
DOI:https://doi.org/10.35816/jiskh.v10i1.608

Researh Articel

\title{
Pengaruh Faktor Pengetahuan dan Aksesibilitas Dalam Pemanfaatan Kelambu Insektisida
}

Mariana Isir', Alva Cherry Mustamu' ${ }^{2}$ Adriana Egam ${ }^{3}$

$12{ }^{3}$ Poltekkes Kemenkes Sorong, Indonesia

\begin{tabular}{l}
\hline Article Info \\
Article History: \\
Received: $28-03-2021$ \\
Reviewed: $20-04-2021$ \\
Revised: $06-05-2021$ \\
Accepted: $30-05-2021$ \\
Published: $30-06-2021$
\end{tabular}

Keywords Kehamilan;

Malaria;
Kelambu insektisida;

\section{Abstrak}

Pengantar; Penyakit malaria cukup banyak penderitanya dan masih merupakan masalah kesehatan masyarakat karena angka morbiditas dan mortalitasnya yang masih tinggi. Penyakit infeksi ini, dapat menyebabkan kematian terutama pada kelompok resiko tinggi yaitu bayi, anak balita dan ibu hamil. Salah satu kelompok yang rentan terhadap malaria adalah ibu hamil. Tujuan; Penelitian ini bertujuan untuk mengetahui pengetahuan, aksesibilitas dan pemanfaatan kelambu insektisida selama kehamilan. Metode; Jenis penelitian yang digunakan adalah Deskriptif Analitik. Dengan pendekatan Cross sectional dengan jumlah smpel 78 ibu hamil dengan cara akidental sampling. Analisis data dilakukan dengan menggunakan uji frekuensi. Hasil; bahwa 57,69\% responden mengetahui tentang kelambu insektisida dari media masa seperti internet, surat kabar, social media. sebanyak $65,38 \%$ responden memiliki setidaknya 1 kelambu insektisida di rumah mereka yang didapatkan dari puskesmas (55,13\%). sebanyak 34,62\% responden menyebutkan bahwa kelambu insektisida diberikan pada mereka pada saat telah trimester ke-3 usia kehamilan. Namun sebanyak 35,9\% responden belum mengunakannya dengan benar. Responden berharap bahwa kelambu insektisida harus diberikan secara gratis (43,59\%). Kesimpulan; Semua wanita hamil telah mengetahui tentang kelambu insektisida namun penggunaannya belum benar. Seluruh responden siap menggunakan kelambu insektisida jika informasi yang memadai disediakan dan kelambu tersedia dengan harga terjangkau atau disediakan secara gratis

Abstract. Introduction; Malaria suffers quite a lot and is still a public health problem because of its high morbidity and mortality rates. This infectious disease can cause death, especially in high-risk groups, namely infants, toddlers, and pregnant women. One of the groups that are vulnerable to malaria in pregnant women. Aim; This study aims to determine the knowledge, accessibility, and use of insecticide bed nets during pregnancy. Method; This type of research is descriptive-analytical. With a cross-sectional approach with a sample of 78 pregnant women by means of accidental sampling. Data analysis was performed using a frequency test. Result; That $57.69 \%$ of respondents about insecticide bed nets from mass media such as the internet, newspapers, social media. as many as $65.38 \%$ of respondents had at least 1 insecticide bed net in their house obtained from the puskesmas $(55.13 \%)$. as much as $34.62 \%$ of respondents said that insecticide-treated bed nets were given to them at the 3rd trimester of pregnancy. However, 35.9\% have not used it properly. Respondents hoped that insecticide bed nets should be provided free of charge $(43.59 \%)$. Conclusion; All pregnant women are ready to use insecticide bed nets if adequate information and bed nets are available at affordable prices or provided free of charge

\begin{tabular}{ll}
\hline Corresponding author & $:$ Mariana Isir \\
Email & : marianaisir@gmail.com
\end{tabular}




\section{Pendahuluan}

Penyakit malaria cukup banyak penderitanya dan masih merupakan masalah kesehatan masyarakat karena angka morbiditas dan mortalitasnya yang masih tinggi terutama di luar Jawa dan Bali. Penyakit infeksi ini, dapat menyebabkan kematian terutama pada kelompok resiko tinggi yaitu bayi, anak balita dan ibu hamil. Salah satu kelompok yang rentan terhadap malaria adalah ibu hamil. Malaria dapat mengakibatkan berbagai dampak negatif terhadap ibu hamil dan janin yang dikandungnya (Kementerian Kesehatan RI, 2017). Malaria telah menjadi beban kesehatan dunia dan masalah kesehatan masyarakat yang utama di daerah tropis dan subtropis di dunia. Malaria adalah penyakit yang mengancam jiwa yang disebabkan oleh parasit yang ditularkan ke manusia melalui gigitan nyamuk Anopheles betina yang terinfeksi. Malaria dapat dicegah dan disembuhkan (WHO, 2021).

Pada 2019, diperkirakan ada 229 juta kasus malaria di seluruh dunia. Perkiraan jumlah kematian akibat malaria mencapai 409.000 pada 2019. Anak usia di bawah 5 tahun merupakan kelompok yang paling rentan terkena malaria; pada 2019, mereka menyumbang 67\% (274.000) dari semua kematian akibat malaria di seluruh dunia. Total dana untuk pengendalian dan eliminasi malaria diperkirakan mencapai US \$ 3 miliar pada tahun 2019. Kontribusi dari pemerintah negara endemis mencapai US \$900 juta, mewakili 31\% dari total pendanaan (WHO, 2021).

Di Indonesia berdasarkan hasil Riset Kesehatan Dasar (Riskesdas) tahun 2018 kasus kematian akibat malaria menduduki peringkat keenam. Terdapat 1,75 juta kasus malaria yang tersebar di 424 kabupaten dari 576 kabupaten yang ada dan diperkirakan $45 \%$ penduduk Indonesia berisiko tertular malaria (Depkes, 2016). Malaria masih endemis di sebagian besar wilayah Indonesia antara lain Indonesia kawasan Timur seperti Papua, Maluku, Nusa Tenggara, Sulawesi. Indonesia bagian Timur termasuk dalam stratifikasi malaria tinggi (Litbang Kemenkes, 2018). Annual Parasite Incidence (API)untuk kasus malaria di Indonesia bila dilihat per provinsi yang paling paling tertinggi adalah Papua Barat. Menurut laporan World Health Organization (WHO) populasi penderita malaria di Indonesia pada tahun 2012 dengan stratifikasi High transmission (>1 kasus per 1000 penduduk) sebesar 17\% Low transmission (0-1 kasus perseribu penduduk) 44\% dan bebas malaria sebanyak 39\% (Litbang Kemenkes, 2018). Infeksi malaria selama kehamilan merupakan masyarakat yang signifikan masalah Kesehatan dengan risiko yang cukup besar bagi ibu hamil, janinnya, dan bayi yang baru lahir. Wanita hamil mengalami serangan malaria lebih sering dan lebih parah daripada wanita tidak hamil dari daerah yang sama, dan mungkin meninggal karena malaria. Hal ini karena kehamilan mengurangi kemampuan imun melawan malaria. Sekitar 19-24 juta wanita berisiko terkena malaria selama kehamilan ${ }^{10}$. Penyakit ibu terkait malaria dan berat badan lahir rendah sebagian besar disebabkan oleh infeksi Plasmodium falciparum (Aguscik \& Ridwan, 2019; Jabir, 2020). Malaria dalam kehamilan juga berkontribusi terhadap morbiditas dan mortalitas peri-natal yang signifikan. Infeksi malaria diketahui menyebabkan tingkat yang lebih tinggi keguguran, kematian intrauterin, kelahiran prematur, neonatus berat lahir rendah, dan kematian neonatal (Sutarto et al., 2019).

Untuk menanggulangi permasalahan malaria di Indonesia salah satu upaya yang dilakukan adalah dengan pelaksanaan program kelambu berinsektisida atau Impregnated Treated Nets (ITNs) (Rehana \& Mutiara, 2017). Dalam beberapa tahun terakhir, distribusi kelambu berinsektisida tidak memadai, dengan hanya beberapa wilayah pemerintah daerah yang ditargetkan. Hal ini membuat tidak mungkin mencapai saturasi di satu area. Strategi terkoordinasi untuk memberikan 2 kelambu kepada setiap rumah tangga dan melalui serangkaian kampanye. Tujuannya adalah untuk mempromosikan penggunaan kelambu, terutama di kalangan wanita hamil dan anak-anak di bawah usia 5 tahun (Hayati \& Suriani, 2018; Mahmud, 2020). Tidak diketahui apakah penggunaan kelambu yang tidak menyeluruh disebabkan oleh kurangnya pengetahuan tentang kelambu berinsektisida dan kegunaannya, atau karena tidak mendapatkan kelambu berinsektisida, atau karena ada faktor penghambat lainnya. Juga tidak diketahui apakah ibu mampu menggunakan dan pendapat tentang penggunaan kelambu berinsektisida. Masalahmasalah ini yang memotivasi pelaksanaan penelitian ini di ibu hamil di kota sorong menentukan pengetahuan, aksesibilitas dan pemanfaatan kelambu berinsektisida selama kehamilan. Penelitian 
ini bertujuan untuk mengetahui gambaran pengetahuan, aksesibilitas dan pemanfaatan kelambu insektisida selama kehamilan

\section{Metode}

Jenis penelitian yang digunakan adalah deskriptif analitik, dengan pendekatan Cross sectional study. Populasi penelitian terdiri dari semua wanita hamil yang mengunjungi puskesmas di kota sorong dalam waktu 6 minggu penelitian. Sebanyak 78 wanita hamil direkrut menggunakan teknik aksidental sampling dengan kriteria inklusi meliputi: 1) harus seorang wanita hamil; 2) harus melakukan ANC di puskesmas 3) harus bersedia berpartisipasi dalam studi ini. Kriteria eksklusi adalah mereka yang menolak menandatangani formulir persetujuan. Kuesioner penelitian dikembangkan sendiri oleh peneliti dan disusun berdasarkan tujuan penelitian yang terdiri dari 2 bagian yaitu data sosiodemografi dan pertanyaan format tertutup. Koefisien reliabilitas 0,89 diperoleh dengan menggunakan Cronbach's alpha. Proses pengumpulan data dilakukan dengan wawancara setelah mendapat persetujuan responden. Uji yang digunakan adalah uji distribusi frekuensi menggunakan SPSS versi 16. Penelitian ini telah disetujui oleh komite etik poltekkes kemenkes sorong nomor DM.03.05/6/201/2020

\section{Hasil Dan Pembahasan}

Tabel 1

Karakteristik sosiodemografi responden

\begin{tabular}{|c|c|c|c|}
\hline & & & \\
\hline Karakteristik & Kategori & $\mathbf{n}$ & $\%$ \\
\hline \multirow[t]{4}{*}{ umur (tahun) } & $<20$ & 8 & 10,3 \\
\hline & $20-29$ & 38 & 48,7 \\
\hline & $30-39$ & 32 & 41 \\
\hline & $\geq 40$ & 0 & 0 \\
\hline \multirow[t]{4}{*}{ Pendidikan } & Tidak sekolah & 0 & 0 \\
\hline & Sekolah dasar & 12 & 15,4 \\
\hline & SMP/SMA & 34 & 43,6 \\
\hline & Perguruan tinggi & 32 & 41 \\
\hline \multirow[t]{5}{*}{ Riwayat persalinan } & 1 & 13 & 16,7 \\
\hline & 2 & 33 & 42,3 \\
\hline & 3 & 12 & 15,4 \\
\hline & 4 & 12 & 15,4 \\
\hline & $\geq 5$ & 8 & 10,3 \\
\hline \multirow[t]{3}{*}{ Agama } & Kristen & 45 & 57,7 \\
\hline & Islam & 23 & 29,5 \\
\hline & Katolik & 10 & 12,8 \\
\hline \multirow[t]{3}{*}{ Umur Kehamilan } & Trimester 1 & 32 & 41 \\
\hline & Trimester 2 & 21 & 26,9 \\
\hline & Trimester 3 & 25 & 32,1 \\
\hline \multirow[t]{5}{*}{ Pekerjaan } & Ibu Rumah tangga & 23 & 29,5 \\
\hline & Pegawai swasta & 10 & 12,8 \\
\hline & wiraswasta & 12 & 15,4 \\
\hline & pegawai negeri & 12 & 15,4 \\
\hline & pelajar/mahasiswa & 21 & 26,9 \\
\hline \multirow{5}{*}{$\begin{array}{l}\text { Riwayat penyakit malaria } \\
\text { selama hamil }\end{array}$} & 0 & 34 & 43,6 \\
\hline & 1 & 32 & 41 \\
\hline & 2 & 6 & 7,69 \\
\hline & 3 & & 0 \\
\hline & $\geq 4$ & 6 & 7,69 \\
\hline
\end{tabular}

Sumber: data Primer, 2020 
Berdasarkan tabel 1, responden yang berpartisipasi dalam penelitian ini adalah berusia 20-29 tahun (48,7\%) dengan tingkat Pendidikan SMP dan SMA yaitu sebanyak 43,6\% dan saat penelitian dilakukan mereka bertatus pelajar/mahasiswa (26,9\%). Sebagian besar responden telah bersalin sebanyak 2 kali $(42,3 \%)$ dan sedang dalam trimester 1 kehamilan (41\%). dan beragama Kristen $(57,7 \%)$. Sebanyak $43,6 \%$ responden belum pernah mengalami sakit malaria selama hamil.

\section{Table 2}

Pengetahuan ibu hamil tentang pencegahan malaria pada kehamilan dengan menggunakan kelambu insektisida

\begin{tabular}{lrr}
\hline Variabel & $\mathbf{n}$ & $\mathbf{\%}$ \\
\hline Apakah anda pengetahui kelambu insektisida & 45 & 57,69 \\
Ya & 33 & 42,31 \\
Tidak & 14 & 17,95 \\
\hline Darimana anda tahu tentang kelambu insektisida & 21 & 26,92 \\
Puskesmas & 25 & 32,05 \\
Edukasi kesehatan & 13 & 16,67 \\
Media masa (internet, surat kabar, sosial media) & 4 & 5,128 \\
Teman dan sahabat & 1 & 1,282 \\
Keluarga & & \\
Tetangga & 45 & 57,69 \\
Menurut Anda mengapa kelambu insektisida penting selama kehamilan & 12 & 15,38 \\
Mengurangi kontak antara ibu hamil dan nyamuk & 16 & 20,51 \\
Menyediakan rumah bagi nyamuk untuk tinggal & 5 & 6,41 \\
Mengusir nyamuk dari kamar & & \\
Ini adalah instruksi dari puskesmas yang harus diikuti & & \\
\hline
\end{tabular}

\section{Sumber: data Primer, 2020}

Pada tabel 2 kami menemukan bahwa 57,69\% responden mengetahui tentang kelambu insektisida dari media masa seperti internet, surat kabar, social media $(32.05 \%)$ yang menegaskan bahwa kelambu insektisida berguna untuk mengurangi kontak antara ibu hamil dan nyamuk $(57,69 \%)$.

Tabel 3

Akses memperoleh kelambu insektisida

\begin{tabular}{lrr}
\hline Variabel & $\mathbf{N}$ & \multicolumn{2}{c}{$\%$} \\
\hline Apakah Anda memiliki setidaknya satu kelambu & & \\
insektisida? & 51 & 65,38 \\
Iya & 27 & 34,62 \\
\hline Tidak & & \\
\hline Darimana anda mendapatkan kelambu insektisida & 43 & 55,13 \\
Puskesmas & 0 & 0 \\
Pasar & 12 & 15,38 \\
Teman / kerabat & 23 & 29,49 \\
Distribusi rumah ke rumah gratis & & \\
\hline Apakah kelambu insektisida sudah tersedia untuk & & \\
Anda & 27 & 34,62 \\
Iya & 51 & 65,38 \\
\hline Tidak & & \\
\hline
\end{tabular}

Sumber: data Primer, 2020

Pada tabel diatas, sebanyak 65,38\% responden memiliki setidaknya 1 kelambu insektisida di rumah mereka yang didapatkan dari puskesmas $(55,13 \%)$ namun pada saat pembagian, nama keluarga mereka tidak terdaftar sebelumnya $(65,38 \%)$. 
Tabel 4

pemanfaatan kelambu insektisida oleh ibu hamil

\begin{tabular}{|c|c|c|}
\hline Variabel & $\mathbf{n}$ & $\%$ \\
\hline \multicolumn{3}{|l|}{ Kapan Anda mulai menggunakan kelambu insektisida } \\
\hline Sebelum hamil & 21 & 26,92 \\
\hline Selama trimester pertama & 13 & 16,67 \\
\hline Selama trimester ke-2 & 17 & 21,79 \\
\hline Selama trimester ke-3 & 27 & 34,62 \\
\hline \multicolumn{3}{|l|}{ Frekuensi penggunaan } \\
\hline Selalu $\quad$ - & 28 & 35,9 \\
\hline Sering & 31 & 39,74 \\
\hline Kadang-kadang & 19 & 24,36 \\
\hline \multicolumn{3}{|l|}{ Bagaimana Anda menempatkan kelambu nyamuk di rumah anda } \\
\hline $\begin{array}{l}\text { Menggantungnya di atas jendela dan pintu untuk mencegah nyamuk masuk ke } \\
\text { dalam ruangan }\end{array}$ & 15 & 19,23 \\
\hline Menggantungnya di salah satu sudut ruangan & 17 & 21,79 \\
\hline $\begin{array}{l}\text { Menggantungnya di atas tempat tidur, tetapi kelambu bersentuhan dengan kulit } \\
\text { saat tidur }\end{array}$ & 28 & 35,9 \\
\hline $\begin{array}{l}\text { Menggantungnya di atas tempat tidur dan tidur di bawahnya dengan } \\
\text { menyelipkannya di bawah kasur, mencegah kontak dengan tubuh }\end{array}$ & 18 & 23,08 \\
\hline \multicolumn{3}{|l|}{ Faktor penyulit penggunaan kelambu insektisida } \\
\hline Terlalu mahal, saya tidak mampu membelinya & 6 & 7,692 \\
\hline Kelambu insektisida menyebabkan panas yang berlebihan dan ketidaknyamanan & 15 & 19,23 \\
\hline Saya tidak tahu bagaimana cara menggantungnya & 12 & 15,38 \\
\hline Saya tidak bisa menggunakannya saat cuaca panas & 15 & 19,23 \\
\hline Rutinitas menaikkannya setiap pagi setelah digunakan sangat membuat bosan & 27 & 34,62 \\
\hline Saya mendengar bahwa kelambu insektisida berdampak negatif pada janin & 2 & 2,564 \\
\hline Saya tidak mendapatkannya ketika dibagikan secara gratis & 1 & 1,282 \\
\hline \multicolumn{3}{|l|}{ Faktor untuk memperbaiki penggunaan kelambu nyamuk } \\
\hline $\begin{array}{l}\text { Informasi yang memadai tentang cara penggunaan kelambu insektisida harus } \\
\text { disediakan }\end{array}$ & 21 & 26,92 \\
\hline Stok kelambu insektisida harus tersedia & 19 & 24,36 \\
\hline Kelambu insektisida harus diberikan secara gratis & 34 & 43,59 \\
\hline Harga kelambu insektisida harus diturunkan & 4 & 5,128 \\
\hline
\end{tabular}

Sumber: data Primer, 2020

Berdasarkan tabel 4, sebanyak 34,62\% responden menyebutkan bahwa kelambu insektisida diberikan pada mereka pada saat telah trimester ke-3 usia kehamilan dan sering menggunakan kelambu tersebut (39,74\%). Namun sebanyak 35,9\% responden Menggantungnya di atas tempat tidur dan kelambu bersentuhan dengan kulit saat tidur karena plafon tumah yang telalu tinggi dan ada beberapa yang tidak mengetahui cara memasang kelambu tersebut. Sebanyak $34,62 \%$ responden menyatakan bahwa Rutinitas menaikkannya setiap pagi setelah digunakan sangat membuat bosan. Responden berharap bahwa kelambu insektisida harus diberikan secara gratis $(43,59 \%)$.

\section{Pembahasan}

Hasil penelitian menunjukkan bahwa sebagian besar responden mengetahui tentang fungsi kelambu insektisida dan pentingnya pencegahan malaria pada kehamilan. Tanggapan ini tidak mengherankan karena kampanye kelambu insektisida yang terus oleh dinas kesehatan papua barat dan pemerintah kota sorong terus berlangsung. Kesadaran juga diciptakan oleh penyuluh kesehatan masyarakat tentang pentingnya kelambu insektisida. Bahkan di sebagian besar puskesmas, telah menyediakan kelambu untuk dibagikan secara gratis kepada ibu hamil (Niu \& Mofu, 2018). Sumber informasi yang mengungkapkan bahwa banyak yang mengenal kelambu 
insektisida melalui media masa. Hanya sedikit yang mendengar tentang mereka dari teman dan anggota keluarga. Untuk mencapai kesadaran yang lebih besar, diperlukan perluasan pengetahuan publik tentang pentingnya kelambu insektisida melalui pendekatan yang ditargetkan dan multimedia (Lestari et al., 2014; Nabila, 2020). Tanggapan atas pertanyaan lebih lanjut tentang pentingnya kelambu insektisida selama kehamilan didapatkan bahwa mayoritas mengetahui bahwa kelambu insektisida mengurangi kontak ibu hamil dengan nyamuk. Respon tersebut menunjukkan bahwa pengetahuan tentang kelambu insektisida sangat tinggi(Veronica et al., 2020). Hal ini juga tidak mengherankan karena dari profil demografis, mayoritas berpendidikan menengah atau tinggi. Tidak diragukan lagi, tingkat melek huruf yang tinggi memainkan peran penting dalam pengetahuan mereka (Firdaus et al., 2018). Dengan pendidikan, mereka mampu memahami informasi yang disediakan oleh surat kabar dan media massa lainnya. Hal ini menekankan perlunya langkah-langkah untuk meningkatkan taraf pendidikan / status perempuan, terutama pada saat mereka masih berstatus lajang. Hasil ini berbeda dengan hasil penelitian sebelumnya yang menunjukkan bahwa hanya sepertiga responden yang mengetahui kelambu insektisida dalam pencegahan malaria, hal ini menunjukkan bahwa pengetahuannya rendah (Rogayah et al., 2015).

Temuan menunjukkan bahwa mayoritas responden memiliki kelambu insektisida. Hal ini menunjukkan bahwa selama bertahun-tahun, telah terjadi peningkatan yang luar biasa dalam aksesibilitas kelambu insektisida bagi wanita hamil. Temuan juga mengungkapkan bahwa di antara responden yang memiliki kelambu insektisida, mayoritas mendapatkan dibagikan oleh puskesmas dan pemerintah. Ada peningkatan upaya pemerintah untuk membuat kelambu insektisida tersedia dan dapat diakses oleh wanita hamil; fasilitas kesehatan primer khususnya dilengkapi dengan pasokan kelambu insektisida yang memadai dan didistribusikan secara bebas(Aprillia et al., 2020). Hal ini memudahkan kelompok rentan ini, terlepas dari kelas sosialnya, untuk memiliki setidaknya satu kelambu insektisida. Pemerintah perlu memastikan penyediaan yang aman dan distribusi kelambu insektisida secara gratis. Karena besarnya pasar kelambu insektisida, telah terjadi produksi dan penjualan secara bebas dengan harga terjangkau, yang melengkapi upaya pemerintah untuk menyuplai kelambu ini ke keluarga-keluarga yang ketinggalan kelambu gratis dari pemerintah(Kahar et al., 2020).

Temuan ini mengungkapkan bahwa Sebagian besar ibu hamil memiliki setidaknya satu kelambu insektisida di rumah mereka. Mayoritas mulai menggunakannya bahkan sebelum kehamilan mereka saat ini, dan mereka mengaku sering menggunakan kelambu insektisida. Tanggapan lebih lanjut juga mengungkapkan bahwa sebagian besar wanita belum menggunakan kelambu insektisida dengan benar dengan menggantungnya di atas tempat tidur dan kontak dengan tubuh saat tidur di bawahnya. Temuan ini mengungkapkan bahwa upaya yang dilakukan untuk menciptakan kesadaran tentang kelambu insektisida sejauh ini belum berhasil. Kebanyakan orang sekarang menjadi peka dan sadar akan tanggung jawab mereka sendiri untuk menggunakan kelambu insektisida dengan benar untuk mendapatkan keuntungan darinya (Athhari \& Satria, 2016; Yuriatson \& Asmi, 2020). Hambatan utama penggunaan kelambu insektisida adalah keyakinan bahwa kelambu insektisida mungkin memiliki efek negatif pada wanita dan bayi yang belum lahir. Meskipun pengetahuan yang tinggi tentang keefektifan kelambu insektisida untuk pencegahan malaria saat hamil dan meskipun terdapat pengetahuan/kesadaran yang tinggi tentang kelambu insektisida, beberapa orang tidak memiliki pengetahuan yang memadai untuk menghilangkan kesalahpahaman seputar kelambu insektisida sehingga memungkinkan mereka untuk menerima dan menggunakan kelambu insektisida, terutama mereka yang mendapatkan sumber informasinya dari teman dan kolega, bukan dari puskesmas yang informasinya dapat dipercaya (Chrisnawati \& Suryani, 2020; Halimah et al., 2020).

Penegasan tersebut didukung oleh rendahnya persentase responden yang menunjukkan bahwa mereka telah melakukan penyadaran secara memadai. Hal ini berbeda dengan temuan sebelumnya, di mana hanya sebagian kecil yang percaya bahwa jaring yang dirawat mungkin memiliki efek negatif dan merugikan pada mereka dan bayinya. Alasan lainnya adalah: kesulitan 
dalam menggantungnya dengan benar di atas tempat tidur dan panas yang berlebihan serta ketidaknyamanan yang disebabkan oleh tidur di bawah kelambu insektisida. Instruksi yang lebih baik tentang cara menggantung kelambu insektisida dengan benar harus diberikan untuk memastikan penggunaan yang benar. Juga disarankan agar kelambu insektisida didistribusikan secara gratis atau disubsidi.

\section{Simpulan Dan Saran}

Bahwa semua wanita hamil telah mengetahui tentang kelambu insektisida namun penggunaannya belum benar. Semua wanita hamil siap menggunakan kelambu insektisida jika informasi yang memadai disediakan dan kelambu tersedia dengan harga terjangkau atau disediakan secara gratis; Oleh karena itu, pemerintah didorong untuk melanjutkan penyediaan kelambu insektisida agar cakupannya lebih luas. Petugas kesehatan di semua tingkatan, terutama tingkat dasar, juga didorong untuk meningkatkan kesadaran tentang penggunaan kelambu insektisida yang benar untuk memastikan kemanfaatan penuh.

\section{Daftra Rujukan}

Aguscik, A., \& Ridwan, R. (2019). Pengaruh Status Gizi Terhadap Kejadian Anemia Pada Ibu Hamil Di Daerah Endemik Malaria Kota Bengkulu. JPP (Jurnal Kesehatan Poltekkes Palembang), 14(2), 97-100. https://doi.org/10.36086/jpp.v14i2.417

Aprillia, Y. T., Mawarni, E. S., \& Agustina, S. (2020). Pengetahuan Ibu Tentang Makanan Pendamping ASI (MP-ASI). Jurnal Ilmiah Kesehatan Sandi Husada, 9(2), 865-872. https://doi.org/10.35816/jiskh.v12i2.427

Athhari, H., \& Satria, B. (2016). Pengetahuan Tentang Rumah Sehat Dengan Pencegahan Malaria. Jurnal Ilmiah Mahasiswa Fakultas Keperawatan, 1(1), Article 1.I http://jim.unsyiah.ac.id/FKep/article/view/1465

Chrisnawati, Y., \& Suryani, D. (2020). Hubungan Sikap, Pola Asuh Keluarga, Peran Orang Tua, Peran Guru dan Ketersediaan Sarana Dengan Perilaku Hidup Bersih dan Sehat. Jurnal Ilmiah Kesehatan Sandi Husada, 9(2), 1101-1110. https://doi.org/10.35816/jiskh.v12i2.484

Firdaus, Handayani, \& Alamudi, M. Y. (2018). Skrining Malaria Pada Remaja Di Surabaya Dengan Menggunakan Metode Hapusan Darah. Medical and Health Science Journal, 2(1), Article 1. http://journal.unusa.ac.id/index.php/mhsj/article/view/591

Halimah, H., Linda, D., \& Klaralia, F. (2020). Penerapan Algoritma Naïve Bayes untuk Memprediksi Penyakit Malaria pada Puskesmas Hanura. TEKNIKA, 14(1), 57-63. https://jurnal.polsri.ac.id/index.php/teknika/article/view/2100

Hayati, E., \& Suriani, S. (2018). Hubungan Pengetahuan Dengan Sikap Ibu Hamil Tentang Dampak Penyakit Malaria Pada Kehamilan Di Klinik Adriana Tarigan Belawan. Jurnal Penelitian Kebidanan \& Kespro, 1(1), 6-12. https://doi.org/10.36656/jpk2r.v1i1.68

Jabir, H. N. (2020). Faktor yang Mempengaruhi Perilaku Ibu Hamil dalam Pemeriksaan Kesehatan. Jurnal Ilmiah Kesehatan Sandi Husada, 9(1), 548-553. https://doi.org/10.35816/jiskh.v11i1.346

Kahar, F., Priyatno, D., \& Meo, B. M. (2020). Studi Indeks Eritrosit Pada Pasien Diagnosis Positif Malaria. Sulolipu: Media Komunikasi Sivitas Akademika Dan Masyarakat, 20(2), 175182. https://doi.org/10.32382/sulolipu.v2i20.1735

Kementerian Kesehatan RI. (2017, April 26). Cegah Malaria dengan Kelambu Berinsektisida. Sehat Negeriku.

https://sehatnegeriku.kemkes.go.id/baca/rilis-media/20170426/1320645/cegah-malariakelambu-berinsektisida/

Lestari, Y. E., Wardiah, A., Samino, S., \& Sary, L. (2014). Hubungan Sikap Dan Pengetahuan Ibu Hamil Dengan Penggunaan Kelambu Berinsektisida Long Lasting Insect Net (Llins) Di Wilayah Puskesmas Way Nipah Kab Tanggamus. Holistik Jurnal Kesehatan, 8(1), Article 1. 
https://doi.org/10.33024/hjk.v8i1.94

Litbang Kemenkes. (2018). Hasil utama riskesdas 2018. litbang kemenkes. http://kesmas.kemkes.go.id/assets/upload/dir_519d41d8cd98f00/files/Hasil-riskesdas2018_1274.pdf

Mahmud, Y. (2020). Studi Pemanfaatan Antenatal Care Pada Ibu hamil di Puskesmas AengTowa. Jurnal Ilmiah Kesehatan Sandi Husada, 9(1), 505-511. https://doi.org/10.35816/jiskh.v11i1.337

Nabila, I. (2020). Pengaruh Kehamilan Usia Remaja terhadap Kejadian Anemia dan KEK pada Ibu Hamil. Jurnal Ilmiah Kesehatan Sandi Husada, 9(1), 554-559. https://doi.org/10.35816/jiskh.v11i1.347

Niu, F., \& Mofu, R. (2018). Kepatuahan Menggunakan Kelambu Berisektisida Terhadap Kejadian Malaria Pada Ibu Hamil Di Puskesmas Elly Uyo Kota Jayapura Papua. GLOBAL HEALTH SCIENCE (GHS), 3(3), 200-204. https://doi.org/10.33846/ghs.v3i3.292

Rehana, I., \& Mutiara, H. (2017). Penatalaksanaan Malaria dalam Kehamilan. Jurnal Medula, 7(3), 41-45. https://juke.kedokteran.unila.ac.id/index.php/medula/article/view/819

Rogayah, H., Mahendradhata, Y., \& Padmawati, R. S. (2015). Evaluasi Program Terpadu Pengendalian Malaria, Pelayanan Ibu Hamil Dan Imunisasi di Kabupaten Hulu Sungai Selatan dan Kota Banjarbaru Provinsi Kalimantan Selatan. Jurnal Kebijakan Kesehatan Indonesia: JKKI, 4(1), 26-31. https://doi.org/10.22146/jkki.v4i1.36088

Sutarto, S., Wardani, D. W. S. R., Oktarlina, R. Z., Aryanti, S., \& Indriyani, R. (2019). Risk Factors for Malaria in Pregnant Women. KEMAS: Jurnal Kesehatan Masyarakat, 14(3), 332-339. https://doi.org/10.15294/kemas.v14i3.13443

Veronica, E., Amelia, I., Yunatan, K. A., Chrismayanti, N. K. S. D., \& Mahendra, A. N. (2020). Potensi Kombinasi Ekstrak Daun Kelor (Moringa oliefera) dan Artemisia (Artemisia annua) Sebagai Antimalaria Plasmodium falciparum. Jurnal Ilmiah Kesehatan Sandi Husada, 9(2), 831-841. https://doi.org/10.35816/jiskh.v12i2.415

WHO (2021) Fact sheet about Malaria. https://www.who.int/news-room/factsheets/detail/malaria

Yuriatson, Y., \& Asmi, A. S. (2020). Hubungan antara motivasi belajar dengan prestasi belajar mahasiswa. Jurnal Ilmiah Kesehatan Sandi Husada, 9(2), 971-975.

https://doi.org/10.35816/jiskh.v12i2.449 